This presentation begins by discussing the environment in which policy making takes place and identifying the role of players involved, drawing attention to the complexity of the policy making process. It shows how competing forces, such as beliefs, vested interests, values, habits and financial considerations can lead to important evidence being rejected or ignored by national and international policy makers, sometimes with serious consequences.

The talk also explores the role researchers can play in promoting the flow of evidence from research to policy to implementation by focussing on 5 key issues: generating primary research, conducting systematic reviews of evidence, improving access to relevant evidence, enhancing the use of evidence in policy making, and providing information on how best to scale up programmes. Case studies from LMIC settings, relevant to the EDCTP's remit, will be employed to illustrate the various concepts covered in the presentation.

\title{
PS-003 EVIDENCE-INFORMED POLICY MAKING: CHALLENGES AND OPPORTUNITIES
}

Jimmy Volmink. Stellenbosch University, South Africa

10.1136/bmjgh-2016-000260.3

Evidence-informed health policy making depends on the availability of the results of studies that have assessed what works, what does not work, and what may be harmful. However, even where such evidence exists it will not always be embraced by policy makers or other decision makers. 